\title{
PRÁTICAS EDUCATIVAS FAMILIARES: A FAMÍLIA COMO FOCO DE ATENÇÃO PSICOEDUCACIONAL*
}

\author{
FAMILY EDUCATIONAL PRACTICES: \\ PSYCHOEDUCATIONAL HELP TO FAMILIES
}

Heloisa SZYMANSKI ${ }^{* *}$

\begin{abstract}
RESUMO
Este artigo tem por objetivo refletir sobre a necessidade de se considerar a família como objeto de atenção psicoeducacional a partir da desconstrução da visão naturalizada da mesma. Segue apresentando-a como um contexto de desenvolvimento humano e um locus educacional, que responde à tarefa de socialização, desenvolvendo práticas que exigem saberes específicos, nem sempre disponíveis, em especial para as camadas sociais empobrecidas. Pela complexidade do fenômeno em questão, conclui pela necessidade de desenvolvimento de pesquisas multidisciplinares que construam conhecimento científico e subsidiem práticas na área de atenção psicoeducacional às famílias.
\end{abstract}

Palavras-Chave: Família; Atenção Psicoeducacional à Família; Família e Educação; Práticas Educativas na Família.

\begin{abstract}
This article aims to bring into consideration the family as a focus of psychoeducational help. As a first step in that direction it is presented a critical view of the essentialist perspective on that subject. Then, family is presented as a context of human development and an educational locus that needs specific knowledge and practice in order to accomplish its socialization role. The conclusion points to the need of multidisciplinary research on the subject of psychoeducational help to families, so that scientific knowledge can subsidize practice in that field.
\end{abstract}

Key-words: Family; Psychoeducational help to Families; Family and Education; Educational Practices in Education.

(*) Este trabalho tem apoio do CNPq na forma de bolsa ao pesquisador.

${ }^{* *}$ Programa de Estudos Pós-Graduados em Psicologia da Educação da PUC-SP. Endereço para Correspondência: R. Maranhão, 531 ap. 52 São Paulo/SP - CEP 01240-001 - E-mail: hszymanski@uol.com.br 


\section{I - INTRODUÇÃO}

...de como a adoção de um modelo de família pela sociedade resulta em um modo específico de tratá-la.

Este artigo tem por objetivo refletir sobre a necessidade de se considerar a família como objeto de atenção psicoeducacional, no sentido de um apoio para o desempenho da função educativa que lhe foi expressamente delegada pela sociedade ${ }^{1}$.

Essa atribuição, entretanto, ao contrário do que se observa nas demais instituições também educativas (como a escola), é imposta e vivida ${ }^{2}$ no quotidiano de suas relações com outras instituições, sem que essa mesma sociedade se preocupe em apoiar os responsáveis para sua importante função. Este modo de "tratar" a família está calcado em um modelo que inclui o mito do "dom" feminino para educar crianças, destinando às mulheres a maior carga de responsabilidade nessa missão. Essa crença no "dom" dispensou a sociedade de oferecer um acompanhamento no que se refere às suas atribuições, em especial às famílias que não tiveram acesso a uma educação formal adequada e àquelas que vivem em condições socioeconômicas desfavoráveis.

O processo de socialização se dá no convívio familiar e, em especial, por meio das práticas educativas desenvolvidas com a finalidade de transmitir hábitos, valores, crenças e conhecimentos que se acredita serem úteis para a inserção dos filhos na sociedade. Trata-se de um agir que, em geral, é aprendido por imitação e tende a repetir padrões vividos pelos pais em suas famílias de origem, além de carregar a crença de conhecimentos e habilidades inatas para o desempenho da função de pai e mãe e de que família "sempre foi assim".
Essas crenças refletem um pensamento naturalizante, ou seja, que atribui à biologia a forma patriarcal de organização familiar e as relações entre os gêneros, e defendem a idéia de que as "...funções reprodutoras diferentes de homens e mulheres automaticamente constroem diferenças essenciais nos comportamentos paterno e materno"3 (Silverstein \& Auerbach, 1999:397).

Essa perspectiva, chamada de essencialista e neoconservadora por Silverstein \& Auerbach (1999), desconsidera a família como um fenômeno social e histórico, em que há uma igualdade biológica para a relação de cuidado com o filho. Em outras palavras, “... a maternidade [paternidade] é uma relação de cuidado e não uma tarefa associada ao sexo"4 (Maturana, 1993: 12). Este autor, um biólogo, lembra que, embora as diferenças sexuais entre homens e mulheres sejam biológicas, a maneira de vivê-las é cultural, social e historicamente definida.

A visão "essencialista" de família propõe estrutura, organização e valores definidos, no sentido de ser o "melhor" modo de se viver. É intensamente veiculada pelos meios de comunicação, livros didáticos e por instituições da sociedade, implicando um tratamento dessas instituições em relação às famílias, ${ }^{5}$ que por muito tempo foi aceito, sem questionamentos, até mesmo entre educadores e psicólogos.

Essa família aparece representada, na grande maioria das vezes, como sendo branca, de classe média, composta de pai, mãe, filhos (dois) e avós; pai provedor, ocupando a posição mais alta na hierarquia do poder, e a mãe doméstica, responsável pelo bem-estar e educação da prole. É a família pensada (Szymanski, 1995), o modelo de família ideal oferecido por nossa sociedade. Pensada porque permanece subjacente ao projeto de construção de uma família,

(1) Veja Estatuto da Criança e do Adolescente.

(2) Na forma de cobranças e culpabilizações - das escolas, creches, da justiça e dos meios de comunicação - quando a criança ou os adolescentes apresentam problemas.

(3) Trad. da autora.

(4) Trad. da autora

(5) Quando, por exemplo, as escolas não se organizam para incluir os pais (homens) na troca de informações sobre a criança e delegam a responsabilidade toda para a mãe. O mesmo acontece no atendimento de saúde da criança e até mesmo na justiça, quando medidas de retirada do pátrio poder não são acompanhadas de obrigatoriedade de atenção à família. 
apresenta-se como parâmetro para avaliação e promete constituir-se em passaporte para a felicidade.

As "falhas" nesse processo são atribuídas a "patologias" ou "deficiências" morais, intelectuais ou psicológicas dos pais. Instituições educacionais como escolas e creches aproveitam-se dessa ideologia para culpar a família pelas dificuldades escolares e de relacionamento que crianças e jovens apresentam e, também, para encobrir suas próprias deficiências.

Raramente é considerada a enorme dificuldade da tarefa de criação e educação dos filhos na nossa sociedade complexa, exacerbada pela situação de pobreza, que imprime um árduo regime de vida para pais e mães, associada à deficiência de serviços públicos para essa camada da população. O "modelo" de paternidade voluntária é invocado para colocar a responsabilidade em relação aos filhos exclusivamente nos pais (Nunes, 1994) e, freqüentemente, o caminho da queixa, por ser o mais simples, é escolhido para avaliar a competência das famílias, e evita-se o reconhecimento da necessidade de mudanças estruturais na oferta de serviços eficientes a essa população.

Essa atribuição de culpa às famílias - e às mulheres - se dá, no mais das vezes, com base na comparação com o modelo de família - com a família pensada - e não com base na consideração das vicissitudes do quotidiano - a família vivida (Szymanski, 1995) que se desvela nos múltiplos arranjos que homens e mulheres constroem para conviverem, oferecerem cuidados às crianças e adolescentes e terem um espaço de intimidade e acolhimento afetivo.

Uma forma abrangente de definir a família vivida é: um grupo de pessoas que convivem, reconhecendo-se como família, propondo-se a ter entre si uma ligação afetiva duradoura, incluindo o compromisso de uma relação de cuidado contínuo entre os adultos e deles com as crianças, jovens e idosos. Essa proposta abre espaços para os mais diferentes arranjos e protagonistas, mas tem no cuidado o seu sentido de existir. São soluções que muitas vezes se afastam da proposta do modelo de família nuclear burguesa. A força do modelo hegemônico, entretanto, é tão intensa que pode gerar sentimentos de incompetência para os que escolheram formas alternativas de se organizar.

A forte pressão em direção ao modelo nuclear, com sua estrutura e organização patriarcal mantida na perspectiva essencialista, tem o sentido de integrar a família em um arranjo social que atende a interesses mais amplos da sociedade e da cultura. Qualquer mudança nessa instituição de base - que tem a missão de ser a primeira agência socializadora a transmitir cultura para as gerações mais jovens - acaba por atingir as demais instituições e ameaçar uma ordem social interessada em manter o status quo.

Tenta-se passar a idéia de que as mudanças podem trazer o caos social e lança-se uma cortina de fumaça sobre as reais causas da desagregação moral de nossa sociedade, marcada pela desigualdade social. Muitos teimam em permanecer cegos diante da evidência de que a mera manutenção de um modelo de família não garante a criação de um ambiente adequado de desenvolvimento para seus membros, e que muitos problemas com crianças e adolescentes estão ocorrendo naquelas famílias que apresentam o desenho do modelo tradicional.

\section{II - A FAMÍLIA COMO CONTEXTO DE DESENVOLVIMENTO}

Com a criança o gênero humano começa a cada instante (Buber)

De como se pode olhar para a família como um locus de desenvolvimento humano

É na família que a criança encontra os primeiros "outros" e com eles aprende o modo humano de existir. Seu mundo adquire significado e ela começa a constituir-se como sujeito. Isto se dá na e pela troca intersubjetiva, construída na afetividade, e constitui o primeiro referencial para a sua constituição identitária.

A criança, ao nascer, já encontra um mundo organizado, segundo parâmetros cons- 
truídos pela sociedade como um todo e assimilados idiossincraticamente pela família, que, por sua vez, também carrega uma cultura própria. Essa cultura familiar que lhe é específica apresenta-se impregnada de valores, hábitos, mitos, pressupostos, formas de sentir e de interpretar o mundo, que definem diferentes maneiras de trocas intersubjetivas e, conseqüentemente, tendências na constituição da subjetividade.

Esses procedimentos de inserção do jovem membro no mundo, ou o processo de humanização do mesmo - seu nascimento social e existencial-, manifestam-se em ações, com um sentido definido, que constituem as oportunidades de desenvolvimento para as crianças e adolescentes.

O conceito de desenvolvimento está cada vez mais assumindo um caráter relacional, que... "leva em conta as influências nos múltiplos níveis de proximidade da criança" (Mc Loyd, 1998: 188), o que acaba por desafiar a concepção de "... unilinearidade do desenvolvimento cognitivo, social e moral" (Nunes, 1994: 9).

Esse caráter relacional está presente na definição de desenvolvimento humano apresentada por Bronfenbrenner: "...uma mudança duradoura na maneira como uma pessoa percebe e lida com o seu ambiente"6 (1996: 5). Nessa definição, pode-se perceber o quanto o ser em desenvolvimento é ativo nesse processo de trocas recíprocas com o mundo em que vive, e também em relação com outros ambientes, num contínuo processo de mudança.

Para Bronfenbrenner (1996), o mundo em torno é provocador, desperta disposições, tem aspectos atraentes e negativos. Relevante, na sua concepção, é a importância que atribui ao significado que existe para a pessoa em desenvolvimento das atividades, papéis sociais e relações interpessoais, experienciados nas interações face a face.
O ambiente familiar é propício para oferecer inúmeras atividades que envolvem a criança em ações intencionais, numa situação de trocas intersubjetivas, que vão se tornando mais complexas ou envolvendo mais intencionalidades, em uma perspectiva temporal. Famílias que oferecem às crianças e adolescentes mais atividades organizadas, gradualmente aumentando sua dificuldade, nas quais possam se engajar por períodos de tempo mais longos, facilitam, na proposta de Bronfenbrenner, os processos de desenvolvimento. Essas atividades não só ampliam suas habilidades cognitivas e sociais, como também vão consolidando sua posição na constelação familiar. As trocas intersubjetivas na família, numa situação de apoio mútuo, oferecem oportunidade de desenvolvimento para todos os envolvidos, não só para as crianças.

Esse autor lembra que, tanto o trabalho cooperativo ${ }^{7}$ como a brincadeira, são situações que propiciam desenvolvimento. Refere-se ao fato de que jovens da classe média crescem sem jamais terem cuidado de ninguém, sem jamais terem “....aprendido as sensibilidades, motivações e habilidades envolvidas na ajuda e atendimento de outros seres humanos" (Bronfenbrenner, 1996:43). Essa é uma oportunidade que as famílias das classes trabalhadoras (e não as de classe média) freqüentemente oferecem às suas crianças e que pode ser uma situação de aprendizagem de valores.

Estamos considerando aqui os aspectos sociais e educacionais do desenvolvimento da criança e do adolescente. Citando Nunes (1994), deve ser lembrado "... o conceito de reatividade no desenvolvimento infantil: as sociedades estabelecem ambientes para o desenvolvimento de modos específicos de comportamento que se espera que as crianças apresentem e, no geral, elas crescem da maneira esperada" (Nunes, 1994: 7).

\footnotetext{
(6) Ambiente aqui é entendido como indo muito além das pessoas e objetos envolvidos no espaço físico imediato. Ele é constituído pelas relações entre as pessoas, e é fundamental a natureza destes vínculos interpessoais no processo de desenvolvimento.

(7) Obviamente, não se trata de um trabalho excessivo e que comprometa outras atividades.
} 
Para dar conta das expectativas do grupo social, os pais ${ }^{8}$ oferecem uma condição de desenvolvimento favorável tanto no ambiente físico como no tipo de ações que criam, nas oportunidades que oferecem aos filhos e nos objetivos e estratégias que desenvolvem para enfrentar essa tarefa (Nunes, 1994).

Esse processo envolve, de um lado, as concepções de infância de uma sociedade, ou grupo social, que dizem respeito ao tipo de habilidades e saberes necessários e possíveis de serem transmitidos às crianças, que variam de cultura para cultura ou até mesmo dentro dos diferentes segmentos da sociedade. Do outro lado, tem-se o modus operandi, as estratégias de que os pais se utilizam para a promoção do desenvolvimento dos filhos, em resposta àquelas concepções. Desenvolvimento não é um conceito ideologicamente neutro, pois, como aponta Nunes (1994), apresenta conotações avaliativas que podem se tornar um problema, quando se consideram crianças, jovens e práticas educativas familiares de diferentes culturas, origens ou classes sociais, sob o ponto de vista do grupo dominante.

Ao se pensar em famílias como locus de desenvolvimento, deve-se lembrar que elas divergem quanto à concepção de infância e, em conseqüência, irão possibilitar diferentes oportunidades à criança. Além do mais, podem não ocorrer as condições de desenvolvimento que ela poderia, saberia ou gostaria de oferecer, por razões internas e externas, ligadas a sistemas sociais mais próximos ou mais amplos. Ao levarse em conta a família como um contexto de desenvolvimento, não se pode olhá-la como atuando isoladamente das demais instituições sociais.

A descontinuidade no processo socializador entre as instituições educacionais pode prejudicar o desenvolvimento da criança e do adolescente. Os estudos de Nunes (1994) mostram como a escola desconsidera o conhecimento de matemática entre crianças da classe trabalhadora; desconhece sua capacidade de fazer analogias quando pertencem a um meio social economicamente desfavorecido e focaliza atividades de detalhamento que não foram desenvolvidas no seu ambiente doméstico. Slaughte-Defoe (1995) mostra como a desqualificação da escola quanto à capacidade das crianças vindas de camadas sociais de baixa renda acaba influenciando a família, que passa a conformar-se com a incapacidade dos seus filhos e a tratá-los como incapazes, o que é pior.

As pesquisas de Szymanski (1999), Malavasi (1996), Molnar (1996) e Gandolfo (1998), numa comunidade de baixa renda da periferia de São Paulo, confirmaram os dados acima. Os efeitos da discriminação social tiveram como resultado práticas educativas defensivas, no sentido de desenvolver um processo identitário na negatividade ou medo de serem alvo de discriminação, o que levou os pais a adotarem práticas violentas para evitar que os filhos se tornassem "marginais". Além do mais, a situação de grandes dificuldades econômicas é responsável por um clima de irritabilidade e tensão, que os leva a adotar comportamentos punitivos, arbitrários e inconsistentes, causando irritabilidade, crises de birra, negativismo e sentimentos de inadequação nas crianças (McLoyd, 1998).

Como se pode ver, a família, como contexto de desenvolvimento, é um fenômeno muito complexo, cuja compreensão é dificultada pelo número de condições envolvidas, internas e externas a ela, interdependentes, e que apresentam efeitos cumulativos ao longo do tempo. A relação com o ambiente social mais amplo tem efeitos no modo como age com seus filhos e interfere no tipo de desenvolvimento que promove. O desenvolvimento psicológico da criança é afetado: (a) pela ação recíproca entre os ambientes mais importantes nos quais a criança circula (ex.: família/creche; família/escola); (b) pelo que

\footnotetext{
(8) 'Pais' aqui significa aquelas pessoas responsáveis pelo cuidado contínuo da criança no ambiente familiar. Como lembra Durning (1999), a definição precisa dos atores nesse processo é difícil, dependendo dos arranjos familiares e da cultura em questão. Ver a definição de 'família vivida', que abre a possibilidade do papel de 'pai/mãe' ser desempenhado por outros protagonistas que não o pai ou mãe biológicos.
} 
ocorre nos ambientes freqüentados pelos pais (ex.: trabalho, organizações comunitárias); (c) pelas mudanças e/ou continuidades que ocorrem com o passar do tempo no ambiente em que a criança vive, e que têm efeito cumulativo (Brofenbrenner, 1986). Nesse sentido, é ingênuo achar que medidas pontuais na família possam reverter uma situação que foi engendrada na relação com um contexto mais amplo.

Isso não significa, porém, que não se deva aprofundar o conhecimento do ambiente de desenvolvimento que as famílias oferecem e buscar a compreensão de fatores constitutivos do processo educativo que têm lugar entre elas. Esse conhecimento é necessário, em especial em relação àquelas de baixa renda ou abaixo da linha da pobreza, não só para estudar os efeitos prejudiciais dessa carência no seu desenvolvimento, mas também para conhecer as contribuições que oferecem. Trata-se de buscar informações necessárias para a aplicação de programas de atenção a essas famílias, que não podem partir do pressuposto preconceituoso de que são incompetentes em sua tarefa formadora.

Mas, como lembra Bronfenbrenner (1986), nos estudos a serem desenvolvidos com a finalidade de promover políticas públicas de atenção às famílias, não se trata de focalizar tão somente os processos intrafamiliares referentes à interação pais e filhos, mas também como os processos intrafamiliares são afetados por condições extrafamiliares.

\section{A Dinâmica Intrafamiliar}

Entre esses processos intrafamiliares, está a dinâmica relacional e afetiva entre os membros da família, que constitui uma área do conhecimento sistematizado pela psicologia clínica, em especial na área de terapia familiar, que oferece vários referenciais para análise e compreensão sobre o assunto nessa dimensão intersubjetiva. Trata-se de um fenômeno muito complexo, e as diferentes linhas teóricas focalizam diferentes aspectos do mesmo. Esbarra-se, aqui, com um problema: definir o que é uma família funcional ou uma família que oferece condições de desenvolvimento emocional adequado para seus membros. É um conceito, sem dúvida, difícil de explicar, tanto pelas implicações teóricas e metodológicas como ideológicas, sociais e culturais. Essa definição, talvez, poderá emergir da consideração de família como um contexto de desenvolvimento, sendo funcionais aquelas que oferecem condições para que seus membros atinjam esses objetivos. ${ }^{9}$

As várias linhas teóricas, entretanto, definem funcionalidade e adaptação conforme os aspectos que consideram relevantes na sua concepção de família. Ackermann (1978), um dos precursores dos estudos de família em Psicologia, define uma família adaptada como sendo "... capaz de cumprir e harmonizar todas as funções essenciais [de garantir a sobrevivência e plasmar a humanidade essencial do homem] de forma apropriada à identidade e às tendências das famílias e de seus membros, de forma realista em relação aos perigos e oportunidades que prevaleçam no meio circundante" (p.77) ${ }^{10}$. Como se pode notar, a relação com o meio social mais amplo não pode ser desconsiderada. Ackerman (1978) aponta para sentimentos como afeto, devoção e lealdade como sinais de unidade familiar, além de preocupação com o bem-estar do outro (p.85).

A partir de estudos empíricos, numa perspectiva sistêmica, Olson(1986) define a funcionalidade da família segundo duas dimensões: adaptabilidade e coesão. Adaptabilidade é definida como "a habilidade do sistema familiar em mudar sua estrutura de poder, relações de papéis e regras de relacionamento em resposta a exigências situacionais ou de desenvolvimento" (Green \& al., 1991: 57). A adaptabilidade pode ser rígida (pouca mudança), flexível, estruturada

(9) O que não exclui o conteúdo ideológico presente no conceito de desenvolvimento. Talvez a 'funcionalidade' da família comporte tantas definições quantos os critérios para se definir um 'bom'desenvolvimento.

(10) Trad. da autora. 
ou caótica (muita mudança). O equilíbrio está na família estruturada e flexível, que ofereceria condições adequadas para o desenvolvimento social e emocional de seus membros, segundo Olson.

A coesão refere-se à ligação emocional que os membros da família têm uns em relação aos outros (Green \& al., 1991:56). Também se distribui num continuum, desde o desligamento entre os membros até o superenvolvimento. $\mathrm{O}$ equilíbrio está no meio-termo e é lá que as trocas afetivas fluem mais facilmente, tanto no ambiente familiar como também fora dele.

Minuchin (1982), na sua visão sistêmica, aponta para a necessidade de limites bem estabelecidos entre os subsistemas: pais, filhos, irmãos, com papéis e funções claramente definidos para um ambiente propício ao desenvolvimento. Vê a família com um duplo objetivo de proteção psicossocial a seus membros, via a condição de pertencer que oferece e a de promover uma condição de independência gradual, que prepara os jovens membros para a vida em sociedade. É nesse sentido que a extrema coesão dificulta a independência e o desligamento, não promove o sentimento de fazer parte, essencial para o desenvolvimento da identidade pessoal.

Teóricos da comunicação definem a família, assim como qualquer sistema humano, como um sistema lingüístico, gerador de significados (Anderson \& Goolishian, 1988). "Através do diálogo, os sistemas humanos desenvolvem sua própria linguagem e confirmam seu significado" ... "Significado e compreensão são social e intersubjetivamente construídos" (Anderson \& Goolishian, 1988:372), e para Sluzki (1992)

"nosso mundo social é constituído pela e através de uma rede de múltiplas histórias ou narrativas. Esta ecologia de histórias, com diferentes graus de dominância, em diferentes momentos e diferentes contextos, estabelece as referências dentro das quais tomamos conhecimento de nós mesmos e dos outros, dentro das quais estabelecemos prioridades, cobramos obrigações e privilégios, estabelecemos normas para comportamentos adequados ou inadequados, atribuímos significados e ordenamos os eventos no tempo." ( $p$. 218-219).

Dentro dessa perspectiva, as famílias constroem temas dominantes que definem experiências, significados e interações, resultando em um impacto no desenvolvimento de crianças e adolescentes.

Satir (1980) vê a comunicação como um processo verbal e não-verbal de se fazer solicitações e tentativas de influenciar o receptor em alguma direção. Numa família considerada funcional nessa perspectiva, as comunicações são congruentes, isto é, o verbal e o não-verbal estão na mesma direção, há transparência entre a comunicação de intenções e o respeito à autonomia do outro.

Numa perspectiva fenomenológica existencial, a linguagem, a metalinguagem, o modo de compreensão das experiências vividas e as disposições afetivas predominantes orientam o ser com o outro na família. Essa experiência delineará diferentes configurações e modos de proceder entre os membros do grupo familiar, que podem ser compreendidos como expressão de cuidado ou solicitude, vivida tanto de modo deficiente como autêntico.

Por autêntica entende-se aquela solicitude com o outro em que se

"antecipa a ele em sua existencial possibilidade de ser. Um modo em que não se protege o outro, mas que, antes disso fazse com que ele se volte para si mesmo autenticamente, como pela primeira vez. Este modo de solicitude pertence essencialmente ao autêntico 'cuidar'- isto é, para com a existência do outro e não para "o que" ele cuida; ele salva o outro para tornálo transparente a si mesmo em seu cuidar e para torná-lo livre para si" (Heidegger, M, 1981, p. 41).

"A solicitude, na perspectiva acima, é orientada pela consideração, respeito, paciência, tolerância e esperança. Mas pode, também, orientar-se na forma deficiente, pela desconsi- 
deração, impaciência, intolerância ou negligência, "para as quais a indiferença abre caminho" (p.42). Aqui o ser "com" assume as formas de ser "contra" o outro e "sem" o outro. Uma outra forma deficiente de se viver a solicitude é o que Heidegger chama de "saltar sobre o outro", impedindo-o de cuidar de si mesmo. É quando se desenvolve a dependência e dominação, tácitas ou não" (Szymanski, 2002, p.13).

Nessas perspectivas descritas brevemente, ${ }^{11}$ deve ser levado em conta que processos intrafamiliares são perpassados por extrafamiliares, e as famílias, no decorrer da vida, vão construindo soluções para os desafios trazidos pelo mundo, que nem sempre oferecem situações desfavoráveis ao desenvolvimento de seus membros, mas que podem ser passíveis de mudança.

\section{Fatores extrafamiliares e sua influência na dinâmica familiar}

Em Psicologia, a contribuição dos vários teóricos na área de estudos da família tem sido no sentido de apontar aspectos que são importantes no contexto da vida familiar e que podem dar indicações de como os processos extrafamiliares estão influenciando os intrafamiliares. Tal conhecimento é fundamental para o planejamento de programas de atenção a famílias, juntamente com os dados trazidos pela pesquisa na área de desenvolvimento humano.

A pobreza é uma condição extrafamiliar, que tem influência direta nas relações intrafamiliares. McLoyd (apud Nunes, 1994) destaca algumas das formas como a pobreza pode afetar o desenvolvimento de crianças, focalizando especificamente as relações conjugais e entre pais e filhos:

"a) a pobreza e a privação econômica diminuem a capacidade de uma orientação consistente e protetora por parte dos pais; b) um mediador importante entre dificuldade econômica e sofrimento dos pais é o sofrimento psicológico, resultante de um acúmulo de acontecimentos negativos na vida, condições crônicas indesejáveis e a ausência e ruptura dos elos conjugais; c) privação econômica e pobreza afetam as crianças indiretamente, mediante seu impacto no comportamento dos pais; d) as relações pais/filhos, sob condições de dificuldade econômica, dependem da qualidade das relações entre o pai e a mãe". (McLoyd, 1990:312 in Nunes, 1994).

As informações advindas dessas diferentes áreas de pesquisa devem subsidiar programas de intervenção abrangentes, isto é, que envolvam, além das famílias, outras instâncias sociais. No caso da pobreza, as condições materiais de vida das famílias também precisam ser consideradas.

\section{III - A FAMÍLIA COMO LOCUS EDUCACIONAL}

\section{Práticas familiares com as crianças e adolescentes podem se constituir em atos educativos}

Práticas educativas são aqui entendidas como expressão da solicitude nas ações contínuas e habituais realizadas pela família ao longo das trocas intersubjetivas, com o sentido de possibilitar aos membros mais jovens a construção e apropriação de saberes, práticas e hábitos sociais, trazendo em seu interior, uma compreensão e uma proposta de ser-no-mundo com o outro. Isto inclui o processo reflexivo de desenvolvimento pessoal de todos os membros da família.

Tais práticas envolvem saberes que, mesmo não sendo sistematizados, são o resultado de uma aprendizagem social transmitida de geração para geração; manifestam-se em procedimentos e estratégias de ação; utilizam "material pedagógico"; carregam ideologia, supõem competências

(11) Essas descrições foram apresentadas a título de exemplo, pois não é o objetivo deste trabalho aprofundar a questão da dinâmica relacional e afetiva intrafamiliar. 
e comportam avaliações. São complexas e interdependentes, envolvendo todos os membros da família; não são lineares, comportam ambivalências e ocorrem em meio a uma vasta gama de disposições afetivas. Elas têm o sentido de preparar as novas gerações para a vida social, para a vida no mundo.

Como lembra Lahire (1997), tal processo de socialização é mais eficiente quando há por parte dos mais velhos "tempo e oportunidade de produzir os efeitos de socialização"... "de maneira regular, contínua e sistemática" (p.338). Essa oportunidade traduz-se numa disponibilidade dos adultos em serem intermediários no processo de transmissão do capital cultural ${ }^{12}$ por meio de trocas intersubjetivas e no desenvolvimento do que Lahire chama de estratégias de apropriação, ou seja, de atividades que possibilitem o contato da criança com o conhecimento em questão.

Para a realização dessa tarefa, algumas condições se fazem necessárias: um olhar para a criança como sujeito de ação educativa, reconhecimento do status de educadores por parte dos pais e a proposta de desenvolver uma atividade familiar por um período de tempo que corresponda ao de desenvolvimento e amadurecimento dos filhos (Durning, 1999).

Durning propõe a consideração de dois elementos constitutivos do processo educativo na família: os valores dos pais e os aspectos cognitivos.

Os valores estão imersos num conjunto que inclui os significados das ações que se pretende efetuar e as práticas propriamente ditas. Durning lembra que os valores educativos podem ser de ordem moral, como a honestidade, coragem, ou da ordem de desenvolvimento de competências, como confiança em si, e aprimoramento das capacidades. Esse autor destaca, em relação aos valores, as dimensões cognitiva/avaliativa, que orientam a compreensão do mundo ao redor ('é bom/é mau'); afetiva, que define uma hierarquia de aceitação dos valores ('gosto/não gosto') e conativa, mediadora da ação ('quero/não quero') (p.108).
Esses valores definem relações interpessoais, em que os comportamentos se distribuem no continuum aceitação/rejeição, despertando sentimentos de acolhimento ou hostilidade (comportando, também a ambivalência) e delineiam a tendência autoritária ou democrática (ou displicência) da proposta educativa familiar.

Muitas vezes, o discurso que desvela a família pensada apresenta valores muito diferentes daqueles subjacentes às ações quotidianas, na família vivida. Um discurso dos pais valorizando o diálogo e a autonomia pode diferir de uma prática autoritária e opressora, bem como um discurso que expresse valores rígidos e punitivos pode corresponder a uma prática sem controle ou inconsistente. Essa contradição entre prática e valores deve ser levada em conta tanto nas pesquisas como em programas de educação para a família.

Quanto à dimensão cognitiva nas práticas familiares, é preciso lembrar que as condições de desenvolvimento cognitivo proporcionado pelo ambiente familiar, por meio de suas práticas educativas, relaciona-se com a realização escolar durante a vida das crianças e adolescentes. A escola, tanto ou mais do que a família, tem um papel preponderante na constituição identitária das pessoas em sua inserção futura na sociedade e quanto maior a sincronia entre escola e família, tanto melhor para o desenvolvimento de crianças e jovens.

Considerando-se o processo de socialização como um continuum, a família deve estar preparada para dar as condições necessárias aos seus filhos para que possam cumprir as expectativas da escola. Esta tarefa familiar fica muito prejudicada pela condição de pobreza, principalmente se a entendemos como Amartya Sen (1999), prêmio Nobel de economia:'...a pobreza deve ser vista como a privação de capacidades básicas em vez de meramente

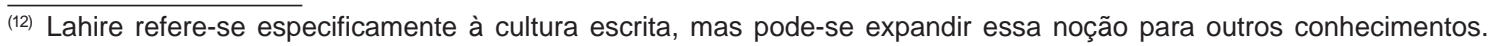


como baixo nível de renda, que é o critério tradicional de identificação da pobreza' (p. 109). ${ }^{13}$

McLoyd (1998), numa cuidadosa revisão, adverte que os efeitos da pobreza são mediados pelas diferenças nos níveis de aprendizagem e de estimulação acadêmica e da linguagem ${ }^{14}$ que a criança recebe na sua família, isto é, pobreza, níveis baixos de educação materna, pouca interação verbal entre pais e filhos, baixa expectativa de escolaridade por parte dos pais, dificuldades afetivas nas relações entre eles e os filhos, estratégias de controle e disciplina deficientes, de condições de vida estressantes no quotidiano que, ${ }^{15}$ além de dificultarem a ação educativa dos pais, podem dificultar a vida acadêmica das crianças e adolescentes.

Lahire (1997), ao estudar histórias de sucesso escolar em crianças de camadas empobrecidas da população, aponta para alguns temas entrelaçados, cuja consideração ajuda a compreender a direção da socialização familiar e sua relação com hábitos e conhecimentos ${ }^{16}$, valores $^{17}$ e regimes disciplinares ${ }^{18}$ valorizados pela cultura escolar. Os temas são os seguintes: as formas familiares da cultura escrita, condições e disposições econômicas, a ordem moral doméstica, as formas de autoridade familiar e as formas familiares de investimento pedagógico (Lahire, 1997: pp. 20-29). Constituem indicadores úteis tanto para o delineamento de projetos de pesquisa como para programas de atenção a famílias. Em seu estudo, mais uma vez verificou-se que as crianças de famílias que proporcionavam a seus filhos condições de relacionamento com a escrita e desenvolviam hábitos, valores e estratégias disciplinares coerentes com as da escola tinham mais condições de sucesso escolar.

Quando a direção da socialização familiar coincide com a da escola, a criança, em geral, segue seu caminho sem grandes dificuldades. No momento em que há uma ruptura, porém, acontece o que Nunes (1994) aponta com muita clareza: “... o sucesso de um sistema pode engendrar o fracasso de outro, no qual se aplicam critérios diferentes para a obtenção de bons resultados de desenvolvimento infantil" (p. 9). Muitas crianças que vêm de ambientes que não favorecem a educação escolar aprendem muito e conseguem muito, mas comparadas com crianças que preenchem todas as expectativas do modelo dominante, são injustamente classificadas como 'fracassadas', simplesmente porque foram avaliadas segundo outro critérios (Nunes, 1994). Como diz Lahire (1998) são "...casos de solidão do aluno no universo escolar: muito pouco daquilo que interiorizou por meio da estrutura de coexistência familiar Ihe possibilita enfrentar as regras do jogo escolar (os tipos de orientação cognitiva, os tipos de práticas de linguagem, os tipos de comportamentos...próprios da escola), as formas de relações sociais" (p. 19).

Em síntese, as práticas educativas são ações que carregam valores, portanto têm um sentido, influem no desenvolvimento das crianças e adolescentes e podem ajudar ou prejudicar a

(13) Esse autor não desvincula a pobreza de renda da pobreza de capacidades, apontando '... que a renda é um meio importantíssimo de obter capacidades'. E como maiores capacidades para viver sua vida tenderiam, em geral, a aumentar o potencial de uma pessoa ser mais produtiva e auferir renda mais elevada, também esperamos uma relação na qual um aumento de capacidade conduzisse a um maior poder de renda, e não o inverso' (Sen, 1999: p. 112).

(14) Como a presença de brinquedos que desenvolvam habilidades motoras e cognitivas como, por exemplo, percepção de cores, formas e tamanhos, lateralidade, comportamento classificatório, discriminação visual, auditiva, olfativa e a atuação contínua de um adulto estimulando a linguagem, além da presença de material escrito no dia-a-dia da família.

(15) Como sofrer ou assistir à violência, desemprego dos pais.

(16) Como familiaridade com a leitura e escrita que, segundo Lahire (1998), nos escritos domésticos - lista de compras, orçamentos, gastos, agenda, calendário - possibilitam a aquisição de hábitos e conhecimentos essenciais para a aprendizagem escolar: tempo objetivado, planejamento no tempo, disposição à regularidade (rotinas), capacidade de prorrogar, ação reflexiva com a linguagem.

(17) Como a moral da perseverança e do esforço, do bom comportamento e conformidade às regras, ordem e limpeza.

(18) Regimes disciplinares que dão importância ao autocontrole, interiorização de normas de comportamento e punições que permitam um tempo de reflexão e compreensão da regra por parte da criança (diferentemente da sanção verbal física brutal imediata). 
inserção destes nas demais instituições da sociedade. Já há um corpo de pesquisas suficientemente amplo que aponta como esse processo de inserção pode ser prejudicado, em nossa sociedade, pela adoção de determinadas práticas e pelo desconhecimento de outras.

Descartando-se a visão naturalizada de família, pode-se depreender que as habilidadese estratégias necessárias para a prática de ações educativas foram aprendidas de modo informal, dentro da própria família, que transmite para as gerações seguintes tais modos de socializar os pequenos. No entanto, podem também ser aprendidas em programas de atenção para famílias.

Indo mais longe, está se tornando uma questão ética informar as famílias das classes economicamente desfavorecidas sobre 0 processo de exclusão de seus filhos e começar a construir, com elas, práticas educativas que possibilitem uma continuidade do seu processo socializador para a escola e para o mundo do trabalho.

Isso não significa responsabilizar os pais pelo aproveitamento escolar, nem apagar a distinção entre educação formal e informal, ou confundir o papel materno/paterno com o papel docente, conforme adverte Carvalho (2000). O sentido dessa atuação é considerar as diferenças entre os ambientes educativos, conscientizar as famílias de baixa renda das condições esperadas pela escola, incorporar suas contribuições na educação formal, respeitar suas opções educacionais, apontar para danos que certas práticas educativas, em especial as que envolvem violência física e psicológica, podem trazer para o desenvolvimento dos filhos e apresentar a possibilidade de uma prática educativa dialógica.

\section{IV - CONSIDERAÇÕES FINAIS: A FAMÍLIA COMO OBJETO DE ATENÇÃO PSICOEDUCACIONAL}

A educação familiar pode ter tanto o sentido de uma prática social - no seu trabalho de atenção às famílias - como o de um campo de conhecimento - no trabalho de pesquisa que vem sendo realizado (Durning, 1999). Trata-se de uma especialidade recente e que está de acordo com a proposta de que pais, na sua função educativa, tanto quanto outros educadores, beneficiam-se de programas de formação. Ao se afastar de uma visão naturalizada de família e olhando-se os pais como educadores, não há como negar a contribuição do conhecimento científico, em especial da psicologia e da educação, para o desempenho da tarefa educativa com os filhos.

A consideração da família como um fenômeno histórico, social, psicológico e educacional leva à consideração da necessidade de um trabalho multidisciplinar para o atendimento da mesma, incluindo a possibilidade de atendimento individualizado e incluindo também as redes socais das quais a(s) família(s) faz(em) parte. Além do mais, para preservar a família como um contexto de desenvolvimento, o planejamento de um programa de atenção deverá contemplar tanto fatores intrafamiliares como extrafamiliares.

Por estarem em jogo crenças e valores arraigados, pode-se supor que projetos de intervenção devam ter uma perspectiva de mudanças a médio e longo prazo, e surge, cada vez mais, a necessidade de pesquisas longitudinais, que avaliem, ao longo do tempo, tanto a eficácia de programas de intervenção, como seu impacto no desenvolvimento dos membros da família, em especial, crianças e adolescentes.

\section{REFERÊNCIAS}

ACKERMANN, N.W. (1978). Psicoterapia de la Familia Neurotica. Trad. N. Watson. Buenos Aires: Ediciones Hormé.

ANDERSON, H. \& GOOLISHIAN, H.A.A.(1988). Human Systems as Linguistic Systems: preliminary and evolving ideas about the implications for clinical theory. Family Process, vol.27, no.4, p.371-393.

BRONFENBRENNER, U. (1986): Ecology of the Family as a Context for Human Development: 
Research Perspectives. In: Developmental Psychology, vol.22, nº 6, p.723-742.

BRONFENBRENNER, U.A. (1996). Ecologia do Desenvolvimento Humano. Trad. M.A.V. Veronese: Porto Alegre: Artes Médicas.

CARVALHO, M.E.P. (2000) Relações entre Família e Escola e Relações de Gênero. Cadernos de Pesquisas, n 110, p. 143-157.

DURNING, P. (1999). Éducation Familiale: acteurs, processus et enjeux. Paris: Presses Universitaires de France.

GANDOLFO, T.S. (1998). Interação Familiare a Construção do Cidadão: uma possibilidade de formação do sujeito social. Dissertação de Mestrado. PUC-SP.

GREEN, R.G., HARRIS Jr., R.N. \& ROBINSON, M. (1991). Evaluating FACES III and the Circumplex Model: 2,440 Families. In: Family Process, vol.30, no.1, p.55-73

HEIDEGGER, M. Todos nós...Ninguém: um enfoque fenomenológico do social. Trad. D.M.Critelli. São Paulo: Ed. Moraes, 1981.

LAHIRE, B. (1997). Sucesso Escolar nos Meios Populares: as razões do improvável. Trad. R.A. Vasques \& S. Goldfeder. São Paulo: Ática.

MALAVASI, A. (1996) A Máscara da Exclusão Escolar a Partir do Universo do Excluído. Dissertação de Mestrado. PUC-SP.

MATURANA, H.R. (1993). Amor y Juego: Fundamentos Olvidados de lo Humano desde el Patriarcado a la Democracia. Santiago: Ed. Instituto de Terapia Cognitiva,

MCLOYD, V. (1998). Socioeconomic disadvantage and Child Development. In: American Psychologist, vol.53, $\mathrm{n}^{\circ}$ 2, p.185-204.

MINUCHIN, S. (1982). Famílias: funcionamento e tratamento.Trad. J.A. Cunha. Porto Alegre: Ed.Artes Médicas.
MOLNAR, D. (1996). Como as Famílias Compreendem o Insucesso Escolar dos Seus Filhos. Dissertação de Mestrado. PUC-SP.

NUNES, T. (1994). O Ambiente da Criança. In: Cadernos de Pesquisa, nº 89, p.5-23.

OLSON, D. H. (1986). Circumplex Model VII: Validation Studies and Faces III. Family Process, 25, p. 337-351.

SATIR, V. (1980). Terapia do Grupo Familiar. Trad. A.Nolli. Rio de Janeiro: Francisco Alves.

SEN, A. (1999). Desenvolvimento como Liberdade. Trad. L.T. Motta. São Paulo: Companhia das Letras.

SLAUGHTER-DEFOE, D.T. (1995). Revisiting the Concept of Socialisation. American Psychologist, vol.50, nº 4, p.276-286.

SLUZKI, C. (1992). Transformations: A Blueprint for Narrative Changes in Therapy. Family Process, Vol 31, p.217-230.

SILVERSTEIN, L.B. \& AUERBACH, C.F. (1999). Deconstructing the Essential Father. American Psychologist, vol.54, p.397-406.

SZYMANSKI, H. (1995) - Teorias e Teorias da Família. Carvalho, M.C.B: A Família Contemporânea em Debate. São Paulo, Educ. Cortez Editora.

(1999) - Práticas Familiares e a Constituição da Identidade Relatório de Pesquisa: Programa de Estudos Pós-Graduados em Psicologia da Educação. PUC-SP.

(2002) - Viver em Família como experiência de Cuidado Mútuo: desafios de um mundo em mudança. Serviço Social e Mudança, no 71, p. 9-25.

Recebido para publicação em 25 de agosto de 2003 e aceito em 22 de abril de 2004. 